\title{
ESTIMATION OF GENETIC PARAMETERS AND BREEDING VALUES FOR ZARAIBI GOATS TRAITS USING SINGLE- AND MULTI-TRAIT ANIMAL MODEL
}

Farrag, F.H.H. ${ }^{1}$; N.A. Shalaby ${ }^{1}$ and H.R. Metawi ${ }^{2}$

1 Animal Production Department, Faculty of Agriculture, Mansoura University, El-Mansoura, Egypt. E-mail: zedan121@yahoo.com

2 Animal Production Research Institute, Ministry of Agriculture, Dokki Giza, Egypt.

\begin{abstract}
A total of 820 Zaraibi goats in the first parity were collected from El-Serw Experimental Station (North Nile Delta) belonging to Animal Production Research Institute, Ministry of Agriculture, Egypt, during the period from 1990 to 2000.

Genetic parameters and breeding values for total milk yield (TMY, $\mathrm{Kg}$ ), lactation length (LL, days), age at first kidding (AFK, months), number of kids born (NKB, kids), number of kids weaned (NKW, kids), litter weight at birth (LWB, Kg) and litter weight at weaning ( $\mathrm{LWW}, \mathrm{Kg})$ in the first kidding were investigated. The statistical analyzes were performed using the MTDFREML (multivariate derivative free restricted maximum likelihood, Boldman et al., 1995). Firstly, single trait animal models were fitted for all traits to obtain heritability estimates. In the second approach, a multi-trait animal model (four traits model) was used to consider NKB, LWB, LWW and TMY traits.
\end{abstract}

The overall means for number of kids born, weaned, litter weight at birth and litter weight at weaning per doe in the first kidding were 1.97, 1.77 kid, 3.6 and 17.67 $\mathrm{Kg}$, respectively. The average of age at first kidding, total milk yield and lactation length were 22.66 months, $269.8 \mathrm{~kg}$ and 258.9 days, respectively. The estimates of coefficient of variations of studied traits ranged between $12.88 \%$ for age at first kidding and $50.71 \%$ for milk production.

Heritability estimates and their standard errors obtained from single-trait of NKB, LWB, LWW, TMY, LL, NKW and AFK were $0.18 \pm 0.05,0.09 \pm 0.06,0.06 \pm 0.05$ $0.24 \pm 0.10,0.12 \pm 0.09,0.15 \pm 0.07$ and $0.09 \pm 0.06$, respectively. While, the obtained estimates from multi-trait animal model analysis of NKB, LWB, LWW and TMY were $0.22 \pm 0.08,0.16 \pm 0.04,0.14 \pm 0.07$ and $0.28 \pm 0.10$, respectively. The heritabilities obtained from multi-trait animal model analysis were higher than those obtained from single-trait animal model analyses. All genetic and phenotypic correlations among production and reproduction traits in the first kidding of Zaraibi goats obtained from multi-trait animal model analyzes (four traits) were positive. The genetic correlations ranged between 0.21 and 0.82 , while the phenotypic correlations ranged between 0.13 and 0.71 . The estimates of genetic correlations between milk yield and each of NKB, LWB and LWW were $0.21 \pm 0.10,0.23 \pm 0.08$ and $0.82 \pm 0.09$, respectively.

The ranges of estimated breeding values (EBVs) obtained from multi-trait animal model analysis for NKB, LWB, LWW and TMY were $0.84 \mathrm{kid}, 1.21,7.44$ and $164.8 \mathrm{~kg}$, respectively. While, the corresponding values obtained from single-trait analysis $0.65 \mathrm{kid}, 0.73,2.64$ and $151.61 \mathrm{~kg}$, respectively. The obtained higher estimates of coefficients of variation, heritability estimates of low to moderate values and wider range of animals breeding values of the Zaraibi goats traits in the first kidding, indicating that potential genetic improvement through selection can be achieved in this flock, especially with multi-trait animal model analysis.

Keywords: Egypt, Zaraibi goats, production and reproduction traits, animal model, genetic parameters, breeding values. 


\section{INTRODUCTION}

Goats play an important socioeconomic role in rural areas. They are prolific and require low inputs for a moderate level of production, reach maturity early and are profitable to keep (Devendra and Burns, 1970). Goats receive less attention than the other livestock species. However, their importance as a potential source of meat, skin, fiber and milk has been documented, particularly in the developing countries. Goats are generally better digesters of crude flbre than sheep, and thus, appear to be better utilizers of poor roughages. Since goats select a different spectrum of herbage than cattle and sheep (Gihad et al. 1980).

The goat population in Egypt reached about 3,960,000 head. However, it produces about 15,100 and 18,000 MT (Metric ton) of milk and meat, respectively (FAO, 2005). The Egyptian Nubian, or Zaraibi, goat, which is kept in the North Delta, shows a promise for high performance. Because of its origin, the Zaraibi is more heat tolerant than most breeds and they are well adapted to local conditions. The Zaraibi has a tendency for having multiple births and moderate milk production. Litter size is a very important factor limiting meat production from goat herds under the intensive system of production. Genetic evaluation systems for dairy goats, based on periodical calculation of predicted breeding values (PBV) for milk yield, reproduction and other economically important traits, have been implemented. Reliable and specific population parameter estimates of heritability and genetic correlations of production traits are essential in predicting breeding values accurately as well as in developing efficient breeding schemes. Therefore, the main objectives of the current study were: (1) to evaluate the productive and reproductive traits of Zaraibi goats under the Northern part of Nile Delta conditions, (2) to estimate heritability $\left(h^{2}\right)$ as well as genetic and phenotypic correlations among traits studied by using multi-trait animal model, (3) to estimate breeding values for these traits and (4) to compare breeding values for production and reproduction traits obtained from single-trait evaluation and multiple trait evaluation, using the first parity records of Zaraibi goats.

\section{MATERIALS AND METHODS}

The data used in the present study were collected from 820 Zaraibi goats in the first parity, during the period from 1990 to 2000. These animals were maintained at El-Serw Experimental Station (North Nile Delta) belonging to Animal Production Research Institute, Ministry of Agriculture, Egypt. Numbers of sires and average daughters per sire (k) were 52 and 15.7, respectively.

Frequent kidding system as one mating each year was practiced by divided the goats into two kidding period groups (June and October). Kids were weaned at 3 months of age. Goat's age at first mating was 18 months of age. At mating, goats were randomly divided into groups each of 30-35 goats, each group were assigned to a fertile buck, which was kept with the group for 35-45 days as a mating period. If the buck was unable to serve the goats it was substituted by another buck after one week of removal. The kids were weighted within 24 hours of birth and monthly until 18 months of age. New 
born kids were identified and according to their type of birth, sex and pedigree.

From December to May, Zaraibi goats grazed on Egyptian clover (Trifolium Alexandrinum). From June to November goats were fed on crops stubbles and green fodder if available, in addition to concentrate mixture 25 $\%$ undecorticated cotton seed, $17 \%$ yellow corn, $11 \%$ soybean meal, $15 \%$ rice bran, $25 \%$ wheat bran, $3 \%$ molasses, $2.5 \%$ Limestone and $1.5 \%$ salt), clover hay and rice straw. Feed allowances were offered twice daily at 7 a.m. and 4 p.m. Drinking water was available twice daily during winter and three times during summer. Before the beginning of mating season 0.25 kilograms concentrate supplement were fed each goat/day. Concentrate mixture given for two weeks and so during the last 2-4 weeks of pregnancy. Some chemical materials add in water dipping to remove of external parasites. Bucks were tested for libido and semen quality before mating season. The goats were vaccinated against the common diseases as scheduled in the farm. The animals of each sub-group were housed in separate semi-open sheds.

The studied traits were total milk yield (TMY, Kg), lactation length (LL, days), age at first kidding (AFK, months), number of kids born (NKB, kids), number of kids weaned (NKW, kids), litter weight at birth (LWB, Kg) and litter weight at weaned (LWW, Kg) in the first kidding. The statistical analyzes were performed using the MTDFREML (multivariate derivative free restricted maximum likelihood, Boldman et al., 1995). Firstly, single trait animal models were fitted for all traits to obtain heritability estimates. In the second approach, a multi-trait animal model (four traits model) was used to consider NKB, LWB, LWW and TMY traits.

Fixed effects included in the model for the total milk yield (TMY) were year kidding (1990 to 2000), season of kidding (1=November-December and $2=$ February - March), litter size (1,2 and 3; 1 =single; $2=$ twin $=3$ = triplet) and covariates for age at first kidding (AFK) and lactation length (LL), while the model for lactation length included the all fixed effects mentioned above without the covariate for lactation length (LL). The fixed effects in the model for reproductive traits were year and season of kidding and covariates for age at first kidding (AFK) and total milk yield (TMY), The vector presentation of the model is: $Y=X \beta+Z u+e$, where $Y$ is the vector of production or reproductive traits; $X$ is the incidence matrix for fixed effects; $\beta$ is the vector of an overall mean and fixed effects in the model; $Z$ is the incidence matrix for random effects; $u$ is the vector of random effect (animals additive genetic effect) associated with the incidence matrix $Z$; and e the vector of random errors normally and independently distributed with $\left(0, \mid \sigma^{2} e\right)$.

Mixed-model equations in the analyzes were solved iteratively based on the variance of the log-likelihood function values, Local convergence was considered attained when the variance of the -2 log likelihoods in the simplex was less than $10^{-7}$. Global convergence was considered attained when the -2 log likelihoods did not change to the five decimal after restarting. Restarts were performed for all analyzes, using the final results of the previous analysis, in order to locate the global maximum for the log likelihoods. Starting values for variance components for four-trait analyzes were obtained from single-trait analyzes on individual traits. The estimated breeding values 
(EBVs) were obtained by back-solution using the MTDFREML program for all animals in the pedigree file for single-trait. Individual breeding values were estimated from single-trait analyses. Breeding values were also estimated from a four-traits animal model analysis.

\section{RESULTS AND DISCUSSION}

The means and standard deviations of studied traits of Zaraibi goats in first parity are shown in Table 1 . The overall mean for number of kids born (NKB), weaned (NKW), litter weight at birth (LWB) and litter weight at weaning (LWW) per doe in the first kidding were 1.97, $1.77 \mathrm{kid}, 3.6$ and 17.67 $\mathrm{Kg}$, respectively. The obtained values in the present study are lower than those (2.2, $1.8 \mathrm{kid}, 3.4$ and $19.3 \mathrm{Kg}$ ) reported by Marai et al. (2002). While, Mourad (1993) found that the litter size at birth of Zaraibi goats in Egypt was 1.78 kids, but Sallam et al. (1988) obtained 1.66 kids, in Baladi goats in Egypt. In general, Devendra and Burns (1983) have listed expected litter sizes for a wide variety of breeds of goats, ranging from 1.0 to 2.3 kids. Bagnicka et al. (2006) reported that the litter size at birth in the first kidding of Polish and Norwegian of dairy goat were 1.51 and 1.23 kids, respectively. Also, Awemu et al. (1999) found that the litter size at birth and at weaning in Red Sokoto goats were 1.8 and 1.7 kids, respectively.

Table 1: Arithmetic means, standard deviations (SD) and coefficients of variation (CV\%) of Zaraibi goats production and reproduction traits in the first kidding.

\begin{tabular}{|l|c|c|c|}
\hline \multicolumn{1}{|c|}{ Trait } & Mean & SD & CV \% \\
\hline NKB (Kids) & 1.97 & 0.61 & 31.12 \\
\hline LWB (Kg) & 3.60 & 1.23 & 34.17 \\
\hline LWW (Kg) & 17.67 & 6.23 & 35.28 \\
\hline TMY (Kg) & 269.8 & 136.8 & 50.71 \\
\hline LL (Days) & 258.9 & 65.39 & 25.26 \\
\hline NKW (Kids) & 1.77 & 0.61 & 34.57 \\
\hline AFK (Months) & 22.66 & 2.92 & 12.88 \\
\hline
\end{tabular}

The average of age at first kidding reported herein was 22.66 months. The present finding was very late than that reported by Bagnicka et al. (2006) 417 and 409 days in Polish and Norwegian dairy goat, also very late (at 21-25 months of age) of age at first kidding were recorded by Gill and Dev (1972). Marai et al. (2002), 691 days, for the Zaraibi goats in Egypt. In this study, higher value of age at first kidding may be due to lower growth rate, as doe which were born as twins, with lighter birth weights and slower growth rate.

In this study, the means of total milk yield and lactation length were $269.8 \mathrm{~kg}$ and 258.9 days, respectively. The milk production of Zaraibi goats was on average less than 1188 and $970 \mathrm{~kg}$ for Saanen goats in England and the USA, respectively (Shelton, 1978). Also, Valencia et al. (2006) reported that the means for total milk yield and lactation length of Saanen goats in Mexico were $800 \mathrm{~kg}$ and 285 days, respectively. The milk production of 
Alpine, Saanen, Toggenburg and Nubian goats in Canada were 740.01, $826.11,757.91$ and $503.86 \mathrm{~kg}$, respectively (Weppert and Hayes, 2004). On the other hand, a lower milk yield and lactation length of the Skopelos dairy goat ( $239.2 \mathrm{~kg}$ and 187 days, respectively) than our findings was reported by Kominakis et al. (2000). Also, Mourad (1992) found that total milk yield and lactation length in the first parity of Alpine goats in Egypt were $231 \mathrm{~kg}$ and 216 days, respectively.

The higher estimates of coefficients of variation (CV) of studied traits in the present study ranged between $12.88 \%$ for age at first kidding and $50.71 \%$ for milk production. Lower estimate recorded by Valencia et al. (2002), who reported that the coefficients of variation for total milk yield and lactation length were 26 , and $7 \%$, respectively. The estimates of coefficients of variation for different traits in the present study indicated that the variability of milk traits of local Zaraibi goats were high and give good opportunity for genetic improvement within flock via selection.

\section{Heritability}

Heritability estimates and their standard errors of different traits studied of Zaraibi goats in first parity were calculated using REML procedures (Boldman et al., 1995). The heritability estimates obtained from single- and multi-trait animal model analyses (four traits: NKB, LWB, LWW and TMY) in the first parity are shown in Table 2. Heritability estimates obtained from single-trait and multi-traits analyses of NKB were $0.18 \pm 0.05$ and $0.22 \pm 0.08$, respectively. The heritability estimated in this study fall within the range of the available reported estimates in the literature. Ricordeau (1981) reported an average $h^{2}$ (5 estimations) of 0.15 with a range of 0.07 to 0.24 . In addition, the range of heritability estimates reviewed by Fogarty (1995) gave a range of $<0$ to 0.34 with a weighted mean of 0.10 (53 estimates) for litter size and $<0$ to 0.54 , with a weighted mean of $0.08 \pm \square 0.08$ for lambs born per ewe joined. $\mathrm{He}$ also added that REML estimates of heritability from an animal model were lower.

Table 2: Heritabilities $\left(\mathrm{h}^{2}\right)$ of production and reproduction traits in the first kidding of Zaraibi goats obtained from single- and multitrait animal model analyses.

\begin{tabular}{|l|c|c|}
\hline \multicolumn{1}{|c|}{ Traits } & $\begin{array}{c}\text { Single-trait } \\
\text { model } \\
\mathbf{h}^{2} \pm \text { S.E }\end{array}$ & $\begin{array}{c}\text { Multi-trait model } \\
h^{2} \pm \text { S.E }\end{array}$ \\
\hline NKB (Kids) & $0.18 \pm 0.05$ & $0.22 \pm 0.08$ \\
\hline LWB (Kg) & $0.09 \pm 0.06$ & $0.16 \pm 0.04$ \\
\hline LWW (Kg) & $0.06 \pm 0.05$ & $0.14 \pm 0.07$ \\
\hline TMY (Kg) & $0.24 \pm 0.10$ & $0.28 \pm 0.10$ \\
\hline LL (Days) & $0.12 \pm 0.09$ & \\
\hline NKW (Kids) & $0.15 \pm 0.07$ & \\
\hline AFK (Months) & $0.09 \pm 0.06$ & \\
\hline
\end{tabular}

The present estimate of heritability of NKB was higher than that obtained by Mourad (1994); 0.025 in African Common goats in Rwanda, Marquez et al. (2003); $0.07 \pm 0.04$ and Bagnicka et al. (2006) 0.14 and 0.18 
Farrag, F.H.H. et al.

of Polish and Norwegian goats, respectively. While, the present estimate was lower than that obtained by Odubote (1992 and 1996) being 0.28 and 0.35 , respectively in the West African Dwarf goats.

In general, the heritabilities obtained from multi-trait analysis were higher than those obtained from single-trait analyses. In this respect, Menendez-Buxadera et al. (2003) found that the heritability for genetic direct effect $\left(h^{2}\right)$ for NKB estimated by univariate animal model $(0 \cdot 14)$ was $40 \%$ lower than the corresponding value for NKB estimated by multi-trait animal model. It has been shown that the genetic components of the two approaches are not the same (Menendez-Buxadera et al., 2003).

The obtained moderate heritability estimate for litter size at birth and high coefficient of variation (31.12\%) indicates the possibility of genetic improvement in litter size of Zaraibi goats in Egypt under the applied production system. However, the selection strategy related to litter size at birth, as a single trait, must be considered with caution, because some negative correlated effects will be expressed. Increases in loss of kids will be associated with improved NKB as indicated from the large and unfavourable correlations between NKB and loss of kids. These unfavourable relationships may also be related to the negative correlations between NKB and birth weight (Menendez-Buxadera et al., 2003). In the same herd, genetic improvement goals should be changed and evaluated under the alternative production system.

Heritability estimate for age at first kidding (AFK) in this study were somewhat lower $(0.09 \pm 0.06)$ than that estimated by Bagnicka et al. (2006), who found that heritability estimate for AFK was moderate and equal to 0.13 for Polish goats.

The heritability estimates obtained from single-and multi-traits analyses for milk yield were $0.24 \pm 0.10$ and $0.28 \pm 0.10$, respectively. The obtained values were higher than estimated by Ribeiro et al. (1998) who found that the heritability estimate of milk yield of Saanen goats in Brazil was 0.09. Early literature reviews of heritabilities of milk yield in dairy goats showed estimates ranging from 0.18 to 0.32 (Kennedy et al., 1982; Mavrogenis et al., 1984; Constantinou et al., 1985; Sullivan et al., 1986; Constantinou, 1989; Mavrogenis et al., 1989; Kala and Prakash, 1990 and Rabasco et al., 1993). Estimates obtained by the REML method ranged from 0.29 to 0.31 (Kala and Prakash, 1990; Andonov et al., 1998; Kominakis et al., 2000; Muller et al., 2002; Van der Linde, 2002; Weppert and Hayes, 2004 and Valencia, 2006).

According to moderate heritability and higher coefficient of variation $(50.71 \%)$ for milk yield, these results indicated to good opportunity exists for selection and, therefore, for the genetic improvement through selection has been an important contributor to the dramatic advances in the Zaraibi goats productivity in Egypt.

\section{Genetic and phenotypic correlations}

All genetic and phenotypic correlations among production and reproduction traits in the first kidding of Zaraibi goats obtained from multi-trait animal model analyses (four traits) in this study were positive (Table 3). The obtained genetic correlations ranged between 0.21 and 0.82 , while the 
phenotypic correlations ranged between 0.13 and 0.71 . Genetic correlation between NKB and LWB was found to be $0.52 \pm 0.09$ in the first kidding of Zaraibi goats, while Farrag et al. (2006) found that the genetic correlation between litter size at birth and litter weight at birth was $0.87 \pm 0.08$ in the first lambing of in Rahmani sheep. The estimate of genetic correlation $(0.61 \pm 0.08)$ between NKB and LWW was in the range of 0.42 to 0.65 for Columbia, Polypay, Rambouillet and Targhee sheep as reported by Bromley et al. (2001). The present results suggest that selection to increase litter size at birth would result in a moderate positive response for litter weight weaned. In the contrary, Ligda et al. (2000) found a high negative genetic correlation between litter size and mean litter weight at weaning $(-0.77)$. While, Farrag et al. (2006) found that the estimate of genetic correlation between litter size at birth and litter weight at weaning was 0.78 in Rahmani sheep.

Table 3: Genetic \pm SE (above diagonal) and phenotypic (below diagonal) correlations among production and reproduction traits in the first kidding of Zaraibi goats obtained from multi-trait animal model analyses.

\begin{tabular}{|c|c|c|c|c|}
\hline Trait & NKB & LWB & LWW & TMY \\
\hline NKB & & $0.52 \pm 0.09$ & $0.61 \pm 0.08$ & $0.21 \pm 0.10$ \\
\hline LWB & 0.43 & & $0.68 \pm 0.11$ & $0.23 \pm 0.08$ \\
\hline LWW & 0.49 & 0.56 & & $0.82 \pm 0.09$ \\
\hline TMY & 0.13 & 0.18 & 0.71 & \\
\hline
\end{tabular}

The estimates of genetic correlations between milk yield and each of NKB, LWB and LWW were $0.21 \pm 0.10,0.23 \pm 0.08$ and $0.82 \pm 0.09$, respectively. Positive correlations indicated that milk production may be increased in response to suckling stimuli, but this is not a factor in dairy goats if the kids are taken away and fed by hand (Devendra and Burns, 1983). Williams (1993) found no evidence of an effect of litter size on milk yield. However, Browning et al. (1995) found that Alpine does that had given birth to singles had a lower milk production $(775 \mathrm{~kg})$ than does with twins $(834 \mathrm{~kg})$ and triplets $(903 \mathrm{~kg})$, despite of the removal of kids at birth effect. Also, Sawalha et al. (2005) concluded that milk score and litter weight at 70 day generally seemed to be positively genetically correlated across parities. They add that selection for higher milk score and litter weight at 70 day could be effectively initiated as early as at the first parity measurements and sheep producers could effectively use the subjective milk score to indirectly select for favorable response in litter weight at 70 day in some sheep breeds.

\section{Estimated breeding values (EBV)}

The range of animal estimated breeding values and standard deviations (S.D) of production and reproduction traits in the first kidding of Zaraibi goats obtained from single and multi-trait animal model analyzes are presented in Table 4. The ranges of estimated breeding values (EBV) obtained from multi-trait analysis for NKB, LWB, LWW and TMY were 0.84 kid, $1.21,7.44$ and $164.8 \mathrm{~kg}$, respectively. While, the corresponding values 
obtained from single-trait analysis $0.65 \mathrm{kid}, 0.73,2.64$ and $151.61 \mathrm{~kg}$, respectively.

Table 4: Range of estimated breeding values (EBV) and standard deviations (SD) for the first kidding production and reproduction traits in the first kidding of Zaraibi goats obtained from single- and multi-trait animal model analyses.

\begin{tabular}{|c|c|c|c|c|c|}
\hline \multirow{2}{*}{\multicolumn{2}{|c|}{ Trait }} & \multicolumn{4}{|c|}{ All animals } \\
\hline & & Range & Min & Max & SD \\
\hline \multirow{4}{*}{ 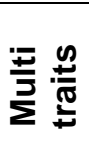 } & NKB & 0.84 & -0.35 & 0.49 & 0.16 \\
\hline & LWB & 1.21 & -0.52 & 0.69 & 0.23 \\
\hline & LWW & 7.44 & -2.40 & 5.05 & 1.39 \\
\hline & TMY & 164.8 & -69.19 & 95.63 & 26.79 \\
\hline \multirow{7}{*}{$\begin{array}{l}\frac{0}{\pi} \\
\frac{\pi}{ \pm} \\
\frac{0}{\sigma} \\
\frac{5}{\omega}\end{array}$} & AFC & 1.91 & -1.03 & 0.89 & 0.38 \\
\hline & NKB & 0.65 & -0.28 & 0.37 & 0.14 \\
\hline & LWB & 0.73 & -0.31 & 0.43 & 0.14 \\
\hline & NKW & 0.58 & -0.19 & 0.39 & 0.11 \\
\hline & LWW & 2.64 & $\begin{array}{l}-1.08 \\
\end{array}$ & 1.57 & 0.51 \\
\hline & LL & 110.40 & -23.61 & 86.80 & 8.23 \\
\hline & TMY & 151.61 & -56.48 & 95.13 & 24.57 \\
\hline
\end{tabular}

The current results showed higher estimate of standard deviations of breeding values for traits in multi-trait than single-trait animal model analyses. The wider range of animals breeding values indicated that there are high genetic variations among animals or sires, which could be possible to genetically improve by selecting animals based on their estimated breeding values for production and reproduction traits in the first kidding. The type and number of traits included in multiple-trait evaluation should depend upon the breeding goal. Pollak and Quaas (1983) found that the multiple-trait model is usually preferred over the single-trait model as the former uses the covariance structure among traits and the records with missing information, both of which are ignored by the latter. Hanford et al. (2005) reported that the average estimates of breeding value from the seven-trait analysis was 0.2 lambs greater than from the single-trait animal analysis. Similar conclusion was obtained by Shalaby (2005).

\section{CONCLUSIONS}

The milk production and reproduction of the studied traits in the first kidding of Zaraibi goats in Egypt showed higher estimates of coefficients of variation, moderate heritability estimates and wider range of animals breeding values, indicating that potential genetic improvement through selection can be achieved in this flock, especially with multi-trait animal model analysis.

\section{REFERENCES}

Andonov, S.; M. Kovac; D. Kompan and V. Dzabirski (1998). Estimation of covariance components for test day production in dairy goat, Proceedings of 6th World Cong. Genet. Appl. Livest. Prod., 24: 145. 
Awemu, E.M.; L.N. Nwakalora and B.Y. Abubakarb (1999). Environmental influences on preweaning mortality and reproductive performance of Red Sokoto does. Small Rumin. Res., 34: 161.

Bagnicka, E.; E. Wallin; M. Lukaszewicz and T. Adnqy (2006). Heritability for reproduction traits in Polish and Norwegian populations of dairy goat. Small Rumin. Res., (In Press).

Boldman, K.G.; L.A. Kriese; L.D. Van Vleck; C.P. Van Tassell, and S.D. Kachman (1995). A manual for the use of MTDFREML. ARS, USDA, Clay Center, NE.

Bromley, C.M.; L.D. Van Vleck and G.D. Snowder (2001). Genetic correlations for litter weight weaned with growth, prolificacy, and wool traits in Columbia, Polypay, Rambouillet, and Targhee sheep. J. Anim. Sci., 79:339.

Browning, R.; L. Browning; M.L. and T. Sahlu (1995). Factors affecting standardized milk and fat yields in Alpine goats. Small Rumin. Res., 18:173.

Constantinou, A. (1989). Genetic and environmental relationships of body weight, milk yield and litter size in Damascus goats. Small Rumin. Res., 2:163.

Constantinou, A.; R. Beuing and A.P. Mavrogenis (1985). Genetic and phenotypic parameters for some reproduction and milk production characters of the Damascus goat. Z. Tierzuchtg. Zuchtgsbiol. 102: 301.

Devendra, C. and M. Burns (1970). Goat production in the tropics. Common Wealth Agricultural Bureaux, Farnham Royal Bucks. England.

Devendra, C. and M. Burns (1983). Goat Production in the Tropics. Commonwealth Agricultural Bureau International, Wallingford, UK, $p$. 183.

FAO. (2005). Food and Agriculture Organization of the United Nations. FAOSTAT Agriculture Data. FAO Statistical Databases. http://faostat.fao.org/default.aspx

Farrag, F.H.H.; N.A. Shalaby and H.R. Metawi (2006). Estimation of genetic parameters using animal model for first lambing and lifetime production traits of Rahmani sheep. J. Agric. Sci., Mansoura Univ., 31: 91.

Fogarty, N.M. (1995). Genetic parameters for live weight, fat and muscle measurements, wool production and reproduction in sheep: a review. Anim. Breed. Abstr. 63:101.

Gihad, E.A.; T.M. El-Bedawy and A.Z., Mehrez (1980). Fibre digestibility by goats and sheep. J. Dairy Sci., 63: 1701.

Gill, G.S. and D.S., Dev (1972). Performance of two exotic breeds of goats under Indian conditions. Indian J. Anim. Prod., 3: 173.

Hanford K.J.; L.D. Van Vleck and G.D. Snowder (2005). Estimates of genetic parameters and genetic change for reproduction, weight, and wool characteristics of Rambouillet sheep. Small Rumin. Res., 57: 175.

Kala, S.N. and B. Prakash (1990). Genetic and phenotypic parameters of milk yield and milk composition in two Indian goat breeds. Small Rumin. Res., 3: 475 . 
Kennedy, B.W.; C.M. Finley and G.E. Bradford (1982). Phenotypic and genetic relationship between reproduction and milk production in dairy goats. J. Dairy Sci., 65: 2373.

Kominakis, A.; E. Rogdakis; C. Vasiloudis and O. Liaskos (2000). Genetic and environmental sources of variation of milk yield of Skopelos dairy goats. Small Rumin. Res., 36: 1.

Ligda, C.; G. Gabriilidis; T.H. Papadopoulos and A. Georgoudis (2000). Estimation of genetic parameters for production traits of Chios sheep using a multitrait animal model. Livest. Prod. Sci., 66: 217.

Marai, I.F.M.; E.I. Abou-Fandoud; A.H. Daader and A.A. Abu-Ella (2002). Reproductive doe traits of the Nubian (Zaraibi) goats in Egypt. Small Rumin. Res., 46: 201.

Marquez, A.P.; J.F. Ponce; V.M. Vega; J. Rodriguez; V.G. Vizcarra; M. Montano and J.N. Guerrero (2003). Estimates of genetic parameters for reproduction and weight in the progeny of Nubian, French Alpine, Saanen, Toggenburgh, and Spanish goats mated to Boer sires. Proceedings, Western Section, American Society of Animal Science Vol. 54.

Mavrogenis, A.; C. Papachristoforou; P. Lysandrides and A. Roushias (1989). Environmental and genetic effects of udder characteristics and milk production in Damascus goats. Small Rumin. Res., 2,:333.

Mavrogenis, A.P.; A. Constantinou and A. Louca (1984). Environmental and genetic causes of variation in production traits of Damascus goats. 2. Goat productivity. Anim. Prod., 38: 99.

Menendez-Buxadera, A.; G. Alexandre; N. Mandonnet; M. Naves and G. Aumont (2003). Direct genetic and maternal effects affecting litter size, birth weight and pre-weaning losses in Creole goats of Guadeloupe. Animal Science 77: 363.

Mourad, M. (1992). Effects of month of kidding, parity and litter size on milk yield of Alpine goats in Egypt. Small Rumin. Res., 8: 41.

Mourad, M. (1993). Reproductive performance of Alpine and Zaraibi goats and growth of their first cross in Egypt. Small Rumin. Res., 12: 379.

Mourad, M. (1994). Estimation of genetic and phenotypic parameters of some reproductive traits of Africa common goats in Rwanda. Small Rumin. Res., 15: 67.

Muller, C.J.C.; S.W.P. Cloete and S.J. Schoeman (2002). Estimation of genetic parameters for milk yield and composition of South African Saanen goats.: Proceedings of the Seventh World Congress on Genetics Application and Livestock Production, vol. 29, 18-23 August, Montpellier, France, pp. 259-262.

Odubote, I.K. (1992). Genetic and non-genetic sources of variation in litter size, kidding interval and body weight at various ages of West African Dwarf goats. Ph.D. Thesis Obafemi Awolowo University, 161 pp.

Odubote, I.K. (1996). Genetic parameters for litter size at birth and kidding interval in the West African Dwarf Goats. Small Rumin. Res., 20: 261.

Pollak, E.J. and R.L. Quaas (1983). Definition of group effects in sire evaluation models. J. Dairy Sci., 66: 1503. 
Rabasco, A.; J.M. Serradilla; J.A. Padilla and A. Serrano (1993). Genetic and non-genetic sources of variation in yield and composition of milk in Verata goats. Small Rumin. Res., 11: 151.

Ribeiro, A.C.; S.A. Queiroz; J.F. Lui; S.D.A. Ribeiro and K.T. Resende (1998). Genetic and phenotypic parameters estimates and genetic trend of milk yield of Saanen goats in southeast of Brazil. $6^{\text {th }}$ World Congress on Genetics Applied to Livestock Production. 24:234.

Ricordeau, G. (1981). Genetics: breeding plans. In: Goat Production. Ed. C.Gall. Academic Press, London:111-169.

Sallam, M.T.; H.A. Hassan and F.N.R. El-Feel (1988). Crossing and some environmental factors, effects on reproductive and growth performance of Egyptian Baladi and French Alpine goats, effects on reproductive and growth performance of Egyptian Baladi and French Alpine goats. Minia. J. Agric. Res. Dev., 10: 1585.

Sawalha, R.; M.G.D. Snowder; J.F. Keown and L.D. Van Vleck (2005). Genetic relationship between milk score and litter weight for Targhee, Columbia, Rambouillet, and Polypay sheep. J. Anim. Sci., 83:786.

Shalaby, N.A.(2005).Genetic evaluation for milk production, reproduction traits and persistency of lactation using single- and two-trait animal model analyses for Friesian cows in commercial herds in Egypt. J. Agric. Sci., Mansoura Univ., 30: 3636.

Shelton, M. (1978). Reproduction and breeding of goats. J. Dairy Sci., 61, 994.

Sullivan, B.P.; B.W. Kennedy and L.R. Schaeffer (1986). Heritabilities fat and protein yields in dairy goats. J. Dairy Sci., 69 (Suppl. 1), 100 (Abstract).

Valencia, P.M.; L.J. Dobler and S.I. Arbiza (2002). Sources of environmental variation affecting lactation and pre-weaning growth characteristics in Saanen goats. Cuban J. Agric. Sci., 36: 117.

Valencia, M.; J. Dobler and H.H. Montaldo (2006). Genetic and phenotypic parameters for lactation traits in a flock of Saanen goats in Mexico. Small Rumin. Res., (In Press).

Van der Linde, J.G. (2002). Genetic evaluation of yield for dairy goats in the Netherlands. In: Proceedings of the $7^{\text {th }}$ World Congress on Genetics Applied to Livestock Production, Session 1, Montpellier, France, pp. 14.

Weppert, M. and J.F. Hayes (2004). Direct genetic and maternal genetic influences on first lactation production in four breeds of dairy goats. Small Rumin. Res., 52: 173.

Williams, J.C. (1993). Influence of farm, parity, season and litter size on the lactation curve parameters of white British dairy goats. Anim. Prod., 57:99. 
Farrag, F.H.H. et al.

تقدير المعالم الوراثية والقيم التربويـة لصفات المـاعز الزرايبس باستخدام التحليل

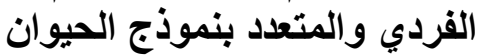

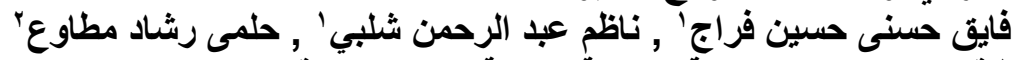

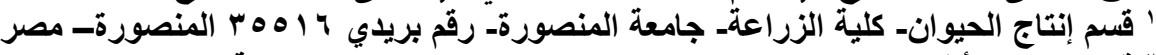

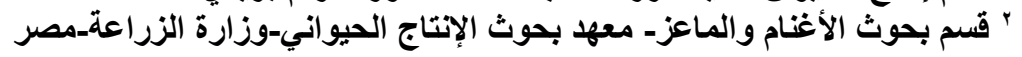

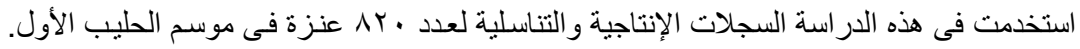

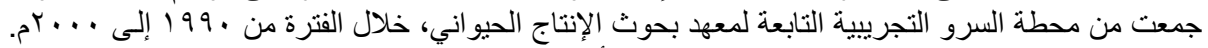

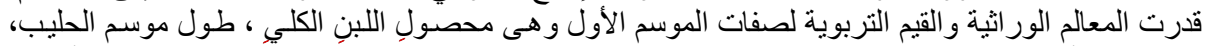

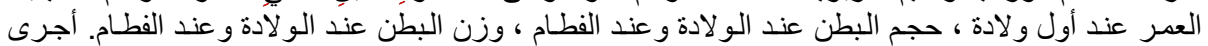

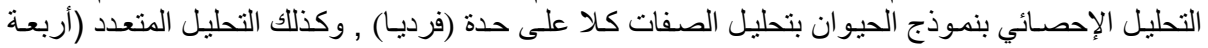

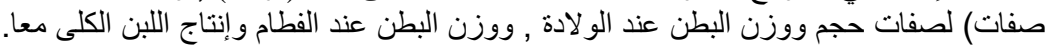

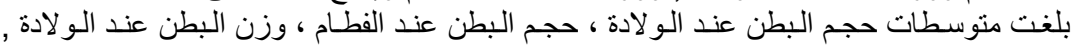

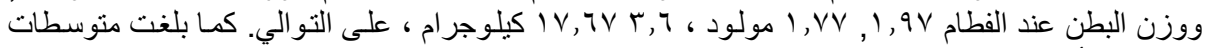

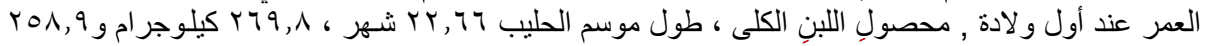

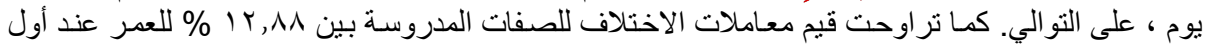

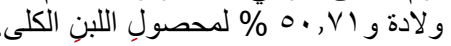

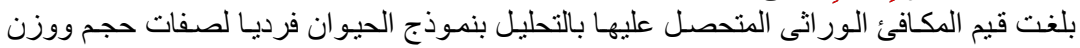

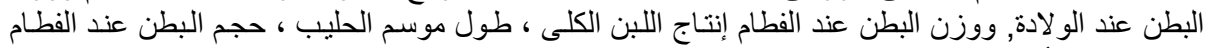

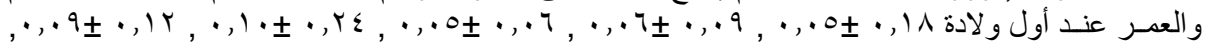

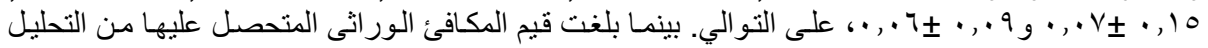

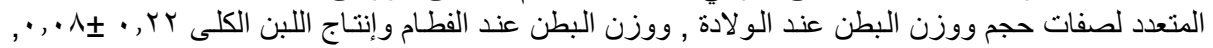

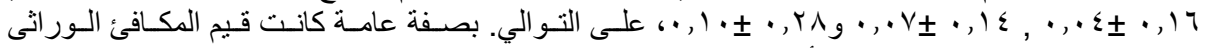

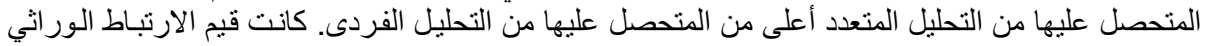

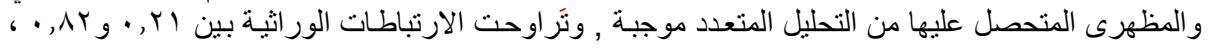

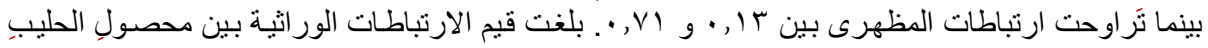

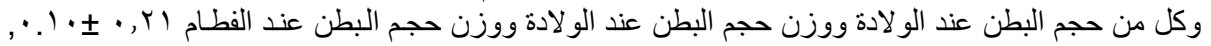

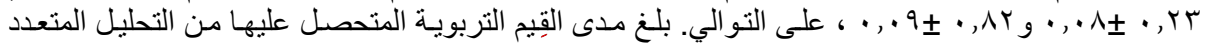

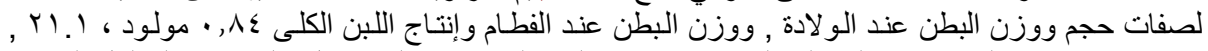

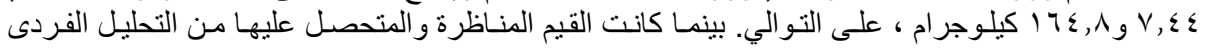

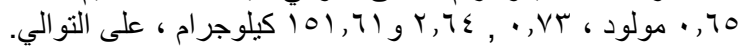

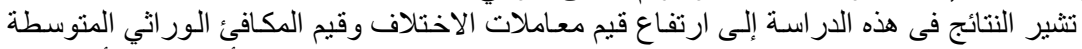

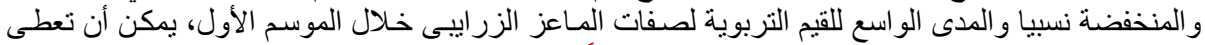

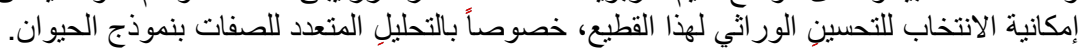

